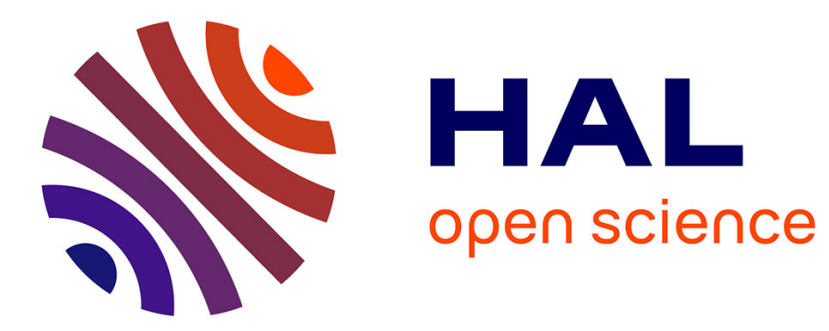

\title{
Photodynamic therapy for atherosclerosis. The potential of Indocyanine Green
}

\author{
Sabrina Houthoofd, M Vuylsteke, Serge Mordon, I Fourneau
}

\section{To cite this version:}

Sabrina Houthoofd, M Vuylsteke, Serge Mordon, I Fourneau. Photodynamic therapy for atherosclerosis. The potential of Indocyanine Green. Photodiagnosis and Photodynamic Therapy, 2019. hal02504731

\section{HAL Id: hal-02504731 \\ https://hal.science/hal-02504731}

Submitted on 11 Mar 2020

HAL is a multi-disciplinary open access archive for the deposit and dissemination of scientific research documents, whether they are published or not. The documents may come from teaching and research institutions in France or abroad, or from public or private research centers.
L'archive ouverte pluridisciplinaire HAL, est destinée au dépôt et à la diffusion de documents scientifiques de niveau recherche, publiés ou non, émanant des établissements d'enseignement et de recherche français ou étrangers, des laboratoires publics ou privés. 


\title{
Photodynamic therapy for atherosclerosis. The potential of Indocyanine Green.
}

\author{
S. Houthoofd ${ }^{\mathrm{a},{ }^{*}}$, M. Vuylsteke ${ }^{\mathrm{b}}$, S. Mordon ${ }^{\mathrm{c}}$, I. Fourneau $^{\mathrm{a}}$ \\ ${ }^{a}$ Department of Vascular Surgery, University Hospital Gasthuisberg, Herestraat 49, Leuven, Belgium \\ ${ }^{\mathrm{b}}$ Department of Vacular Surgery, Sint-Andriesziekenhuis, Tielt, Belgium

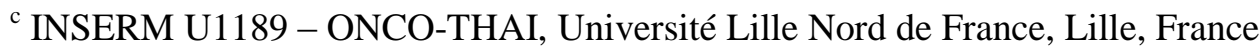

Corresponding autho: Sabrina Houthoofd

Department of Vascular Surgery,

University Hospital Gasthuisberg,

Herestraat 49,

3000 Leuven

Belgium

E-mail: sabrina.houthoofd@uzleuven.be

\section{Abstract}

\begin{abstract}
Aim: The aim of this article is to summarize and review the use of photodynamic therapy for the treatment of atherosclerotic plaque and the prevention of intimal hyperplasia. Different photosensitizers are discussed and more specific the role of indocyanine green as a potential photosensitizer.
\end{abstract}

Methods: Literature search with focus on the use of photodynamic therapy in atherosclerosis, the mechanism of action and the different photosensitizers for photodynamic therapy.

Results: In-vitro and in-vivo studies confirm the use of photodynamic therapy for the treatment of atherosclerosis and the prevention of restenosis. Non-specific accumulation of photosensitizer and thus phototoxicity, remains an important problem. Indocyanine green is a photosensitizer 
with features in favor of photodynamic therapy. The results of photodynamic therapy with indocyanine green point towards the potential of indocyanine green as a photosensitizer in photodynamic therapy for atherosclerosis.

Conclusion: Photodynamic therapy is a promising tool for atherosclerosis. Many of the studied photosensitizers have toxic effects. Indocyanine green might be a good photosensitizer for the use of photodynamic therapy in atherosclerosis. These data justify further research to the use of indocyanine green as a photosensitizer in the treatment of atherosclerotic plaque both de novo or in restenotic lesions.

\section{Keywords}

Atherosclerosis; Intimal hyperplasia; Photodynamic therapy; Photosensitizers; Indocyanine green. 


\section{Introduction}

Atherosclerotic cardiovascular disease is a worldwide health problem associated with high morbidity, mortality and cost of care. The burden of disease remains high in both developed and developing countries due to the increased prevalence of atherosclerosis risk factors. Major risk factors include smoking, hyperlipidemia, hypertension, diabetes and aging. Lower extremity peripheral arterial disease affects approximately 200 million adults worldwide. The prevalence of peripheral arterial disease increases progressively with age. As a result, peripheral arterial disease is a growing clinical problem due to an aging population. Cigarette smoking correlates significantly with cardiovascular disease. On average, a diagnosis of peripheral arterial disease is made approximately a decade sooner in smokers than nonsmokers. Hypertension together with smoking is a major factor for progression of peripheral arterial disease in patients with diabetes mellitus. Diabetes patients have more advanced arterial disease at initial diagnosis and poorer outcomes than nondiabetic patients. Treatment of hyperlipidemia decreases the risk of progression of peripheral arterial disease [1]. Peripheral arterial disease results in impaired oxygen delivery to leg tissues. Most people with peripheral arterial disease will never experience critical limb ischemia [2]. However, even without critical limb ischemia, patients with peripheral arterial disease have significant functional impairment that manifests itself as poor walking capacity and thus poor physical activity [3]. 
The desire to alleviate symptoms and to maintain function with minimal morbidity and reduced hospitalization in patients with peripheral arterial disease has led to an upward trend in endovascular lower extremity arterial procedures. Percutaneous transluminal angioplasty has a high initial success rate. Stents prevent early elastic recoil and late constrictive remodeling, and they are used to maintain lumen volume when compromised by a flow-limiting dissection or residual stenosis after treatment with atherectomy or balloon angioplasty [3]. Mechanical and pharmacologic adjuncts to percutaneous transluminal angioplasty may reduce dissections and improve patency. For example, drug-coated balloons have reduced stent use in shorter lesions, but longer and more complex lesions often require stenting [4].

Without exception, all interventions designed to treat atherosclerotic occlusive disease are prone to restenosis. Restenosis severely limits the overall efficacy of these interventions and can occur in up to $80 \%$ of patients. The process involves a complex cascade of reactions that result in luminal narrowing through a combination of neointimal hyperplasia and constrictive remodeling $[5-8]$.

The prevention and treatment of restenosis in the lower extremity are among the greatest unmet challenges in vascular surgery. Among several new therapeutic approaches to tackle the problem of restenosis, photodynamic therapy presents a promising alternative. Photodynamic therapy has the capacity to eradicate inflammatory cells, promote vascular healing and debulk the plaque. This therapy can be an interesting alternative to the use of drug-coated balloons or stents. 


\section{Principle of photodynamic therapy}

Photodynamic therapy is widely used for several diseases. It involves a combination of light, photosensitizer and oxygen dissolved in the tissue being treated. The photosensitizing drug is selectively absorbed within the tissues targeted for therapy. When photosensitizers are administered, they accumulate to a greater degree in hyperproliferating cells, such as those in malignant tumor and atherosclerotic lesions, than in normal cells $[9,10]$. The photosensitizer remains dormant until it is activated by light of a very specific wavelength [11]. The light that activates the photosensitizer is produced by a light source and is often transmitted through specially modified fiber optics. The resulting photochemical reaction destroys diseased cells without affecting surrounding normal tissue.

Selectivity renders photodynamic therapy appealing in peripheral arterial disease, in which other endovascular approaches carry a substantial risk of damage to the normal arterial wall [12]. Recent advances in laser technology and endovascular light delivery systems have broadened the scope of photodynamic therapy especially for atherosclerotic applications [13].

\section{Mechanism of photodynamic therapy action}

Photodynamic therapy demands three basic elements: 1) photosensitizer with selectivity for the target tissue, 2) a light source causing activation of the photosensitizer and 3) oxygen dissolved in the tissue being treated. 
The photodynamic therapy response begins with accumulation of photosensitizer in the target tissue. Subsequently the tissue is illuminated at the wavelength that favors maximal absorption by the photosensitizer. The resultant photobiological response is direct cell apoptosis and delayed necrosis from neovascular damage. The time interval between initiation of damage and vascular events vary from tissue to tissue and with different sensitizers. The time course of tissue response to photodynamic therapy can also be manipulated by varying the time interval between drug injection and light delivery and/or drug dose [14]. Vascular mechanism of photodynamic therapy is efficient in the case of cancer treatment. The main aim of vascular mechanism is maximal killing by inducing tumor shutdown. Microcirculation dysfunction is induced by vessel occlusion and vessel collapse. The photosensitizer serves as a catalyst for energy transfer. Light absorption leads to the release of cytotoxic singlet oxygen and release of other reactive oxygen species (Fig. 1). It is believed that this molecule is responsible for the subsequent vessel structural and functional alterations [13].

The main role of photodynamic therapy in the treatment of atherosclerotic plaque is to generate reactive oxygen species that interfere with cell survival and thus the remodeling process. An important feature of photodynamic therapy is that we only notice cell death in those illuminated areas in which there is adequate presence of the photosensitizer. Severe cellular damage is noted in atheromatous areas after light exposure. However, there is preservation of the intact elastic lamina and of normal collagen in the adventitia, suggesting that the integrity of the vessels is conserved. The extensive cell death is consistent with the regression of the atherosclerotic plaque [14-16]. 
In addition to plaque regression, photodynamic therapy can be applied to prevent restenosis. Restenosis is a complex mechanism that includes plaque collapse, vasoconstriction, thrombosis and remodeling, and proliferation of smooth muscle cells [17,18].

Following endothelial injury, there is vascular smooth muscle cell proliferation and migration resulting in intimal hyperplasia and narrowing of vessel lumen (Fig. 2). Reducing or inhibiting smooth muscle cell migration and proliferation is an effective treatment in the prevention of restenosis. Photodynamic therapy leads to inactivation of basic fibroblast growth factor thus inhibits smooth muscle cell proliferation and migration thereby preventing neointimal hyperplasia $[19,20]$.

\section{Cardiovascular Applications of photodynamic therapy}

The role of photodynamic therapy is twofold. Photodynamic therapy has been tested for treatment of atherosclerotic plaque (Table1) but it can also be applied to prevent restenosis (Table 2) [12,21].

\section{Photodynamic therapy for atherosclerosis}

Selective accumulation within the atherosclerotic plaques was demonstrated with porphyrin based photosensitizers. In a rabbit atherosclerosis model, hematoporphyrin uptake was observed through the thickness of the plaque with a concentration gradient from luminal surface towards aortic wall [22]. In this study hematoporphyrin photodynamic therapy inhibits smooth muscle cell growth and decreases intima/media ratio of atheroma after 7 or 14 day post photodynamic 
therapy as compared with the control group. Major drawbacks for the use of hematoporphyrin photosensitizers in clinical setting are the cutaneous photosensitivity and inadequate penetration of 630-nm light through endoluminal blood [23,24]. Therefore, other photosensitizers were developed and tested.

Verteporfin, a so-called second-generation photosensitizer derived from hematoporphyrin, was found to be taken up by atherosclerotic plaque of hyperlipidemic rabbits and miniswine. It is able to bind with endogenous low-density lipoproteins (LDL) and induces apoptosis when activated by light. Preassociation with LDL enhanced accumulation of this photosensitizer in atherosclerotic tissue when compared with normal artery. These studies show that selective uptake and retention of photosensitizer in atherosclerotic plaque is feasible and subsequent light activation of the accumulated photosensitizer could lead to highly selective removal of atherosclerotic plaque. $[25,26]$. Phthalocyanines derivates proved uptake by atherosclerotic plaques in rabbits. Rabbits with diet-induced atheromatous plaques were killed following intravenous administration of copper phthalocyanine tetrasulfonate. The concentration of the dye in atheromatous plaques was 2.6 times higher than in normal vessel wall. [27].

5-aminolevulinic acid based photodynamic therapy for treatment of atherosclerotic plaque was conducted in rabbits and pigs. The concentration was 9 fold higher in plaque compared to normal aortic wall [-29-30]. 


\section{Photodynamic therapy for intimal hyperplasia}

In vitro investigations support the concept that photodynamic therapy inhibits growth of smooth muscle cells. Dartsch et al $[30,31]$ demonstrated that SMCs from arteriosclerotic human arteries are destroyed by Photofrin in combination with ultraviolet light. Photodynamic therapy with phthalocyanine on bovine aortic endothelial cell preparations in vitro induces changes in the extracellular matrix: smooth muscle cell proliferation and migration are inhibited and endothelial cell proliferation is enhanced. These induced responses may be beneficial to vascular remodeling and reduce the restenosis response [32]. LaMuraglia et al [33] even showed that there is preferential uptake of the photosensitizer phthalocyanine in the highly cellular regions of restenosis, thus suggesting that photodynamic therapy can be applied to both therapy and prophylaxis of restenosis.

In vivo studies were performed in different animal models like rats, rabbits, swine and monkey [34-42]. They all have promising results concerning the use of photodynamic therapy but show great variety in optimal dose of used photosensitizer, time interval and used light source.

Ortu et al [37] used phthalocyanine to inhibit intimal hyperplasia in a rat carotid injury artery model. Similar work was done by the group of Eton et al [38,39]. Photofrin was able to diminish intimal hyperplasia 1 week after endothelial injury. The same observation, 1 to 2 weeks after endothelial injury, was established by Asahara et al [40] in their rabbit model when using hematoporphyrin. A study from Hsiang et al [41,42] emphasizes the fact that photodynamic therapy after intimal injury should be given within the first week after endothelial injury, before significant intimal hyperplasia has occurred. Uptake of photosensitizer photofrin in balloon injured external iliac arteries of New Zealand White rabbits was minimal 2 weeks after injury. 
Several clinical studies were conducted to show the safety and efficacy of photodynamic therapy in the prevention of restenosis. In 1999 Jenkins et al [43] performed the first clinical trial. To prevent restenosis after angioplasty, 7 patients underwent adjuvant arterial photodynamic therapy using oral 5-aminolevulinic acid. Mild side-effects as nausea and facial erythema have been described. The study suggested that photodynamic therapy is safe and no evidence of restenosis was observed during 6 months follow-up.

Rockson et al [44] investigated motexafin lutetium as photosensitizer in phase I and II trials. Patients received a single dose of motexafin lutetium before percutaneous intervention. The studies showed safety of motexafin lutetium photodynamic therapy. The need for selection of optimal drug and light dose is stressed. The optimal motexafin lutetium dose and light energy dose were defined in the study by Kereiakes et al [45]. Motexafin lutetium was administered to 79 patients by intravenous infusion 18 to 24 hours before percutaneous coronary intervention with stent deployment. Photoactivation was performed after balloon predilatation and before stent deployment. Motexafin dose 2 to $3 \mathrm{mg} / \mathrm{kg}$ and light fluence 100 to $400 \mathrm{~J} / \mathrm{cm}$-fiber were safe and well tolerated. Most commonly observed side effects were peripheral paresthesia and rash, but these were generally mild and self-limited. No serious adverse events related to administration of the photosensitizer or endovascular illumination were observed. No adverse angiographic outcomes were observed at up to 6 months. This phase I drug and light doseescalation study of phototherapy with motexafin lutetium defines important parameters for the application of photodynamic therapy.

Restenosis was also evaluated with photofrin photodynamic therapy. Photofrin was locally delivered 10min before coronary stent implantation. An over-the-wire device designed for localized delivery of solutions through openings located in the balloon segment was used 
(Dispatch ${ }^{\circledR}$ catheter) and tested in 5 patients. Follow-up was uneventful, with absence of major adverse effects [45].

These studies demonstrated photodynamic therapy is efficacious in the prevention of restenosis. Together with major improvements in laser and fiber optic technology, which make local intravascular drug and light delivery possible and as such eliminates problems of insufficient drug/light selectivity, there is a promising role for photodynamic therapy in prevention of restenosis.

\section{The choice of the photosensitizer}

Effectiveness of photodynamic therapy depends on three components: oxygen, source of light with appropriate wavelength and photosensitizer. Appropriate choice of photosensitizer is one of the keys to success. For photodynamic therapy in atherosclerosis, de novo lesions and restenosis, the photosensitizer needs to target the plaque without harming the normal vessel wall. Accumulation of photosensitizer in the plaque is the most important factor associated with the photodynamic therapy effect. Other important features are 1) low or no toxicity without light 2) selectivity for the plaque macrophaques 3) deep tissue penetration 4) targeted activation [13].

More than 400 compounds are known as photosensitizer. Depending on the type of disease and the affected tissue, the appropriate photosensitizers are used.

The first group, now designated as being the first generation of photosensitizers, are porphyrin macrocycles based on hematoporphyrin and its derivatives.. 
Hematoporphyrin was the first of a number of photosensitizers with demonstrable, selective accumulation within the atherosclerotic plaque. There is maximal concentration in the intimal surface layers, diminishing radially into the media $[47,48]$. Despite selective damage of the plaque, hematoporphyrin and photofrin -a more purified derivative of hematoporphyrin-, there is lack of efficacy because $630 \mathrm{~nm}$ light inadequately penetrates endoluminal blood $[24,48]$. Clinical application has also caused severe prolonged cutaneous phototoxicity. Prolonged cutaneous photosensitivity is the major late effect of concern. Acute erythema and edema, blanching and in severe cases complete necrosis of the skin is described. Skin photosensitivity can be diminished by rapid clearance of the photosensitizer due to excretion or sensitizer breakdown $[10,13]$.

Newer second-generation agents with selective localization and minor cutaneous phototoxicity are available. Phototherapeutic capacity in atherosclerosis has been described for the phthalocyanines, chlorins, purpurins and benzoporphyrin (verteporfin)) derivatives. Ideally such new derivatives would fulfill the photodynamic requirements in terms of improved physicochemical and therapeutic properties. But some of these photosensitizers, like phthalocyanines, still have major disadvantages like a slow clearance rate and poor aqueous solubility [13].

The development of the third generation of photosensitizers takes into consideration the improvement mainly related with photosensitizers transport. New or already known photosensitizers are conjugated with antibodies or nanoparticles. One of the major challenges in the use of porphyrins and its derivatives is the delivery of a hydrophobic drug. Therefore, the development of photosensitizer drug delivery systems based on nanotechnology is an emerging approach to photodynamic therapy. 
Several groups have been pursuing an optimization of photodynamic therapy applications by modification of the structure of the photosensitizer to obtain compounds with ideal hydrophobic/hydrophilic properties and increasing the selectivity of the photosensitizer by developing target photosensitizers. (ref Gomes)). The ideal compound in any case is not yet available.

Studies regarding photodynamic therapy for atherosclerosis established photodynamic therapy as a treatment method for de novo or restenosis lesions. But the ideal photosensitizer for that photodynamic therapy is an unresolved question.

\section{Indocyanine green as a possible photosensitizer for photodynamic therapy in atherosclerosis}

\section{Properties of indocyanine green}

Indocyanine green (ICG) was developed in the Second World War as a dye in photography. In 1957 it was tested as a cyanine dye in human medicine. Initially it was used for determing cardiac output, and the hepatic function. ICG has been used for decades in ophthalmology for imaging retinal blood vessels. It is the only near-infrared dye approved by the USA Food and Drug administration for clinical applications. It is commercially available at low cost in a very pure form.

ICG is a tricarbocyanine, a negatively charged ion that belongs to the large family of cyanine dyes. (Fig. 3). ICG is a complex molecular structure and has amphiphilic properties, that is, both hydrophilic and lipophilic properties [50-51]. It is soluble in water $(1 \mathrm{mg} / \mathrm{mL})$ but not readily soluble in saline. Therefore, ICG should be first dissolved in water and only after this diluted with saline if an isotonic solution is needed. But it is also well-known that in aqueous solutions, 
ICG molecules tend to aggregate. The absorption and fluorescence spectrum of ICG is in the near-infrared region. ICG absorbs mainly between 600 $\mathrm{nm}$ and 900nm and emits fluorescence between 750nm and 950nm (Fig. 4 - Fig. 5). The peak optical absorption wavelength of ICG is approximately $800 \mathrm{~nm}$, with a fluorescence wavelength of approximately $810 \mathrm{~nm}$ in water and $840 \mathrm{~nm}$ in the blood. ICG works in the so-called "tissue optical window". For tissue measurement, hemoglobin and water are the main absorbance molecules. Hemoglobin strongly absorbs light at wavelengths shorter than $650 \mathrm{~nm}$, while water absorbs light at wavelengths longer than 900nm. The wavelength between 650 and 900nm, termed the "optical window", has a high transparency because of low light absorbance by hemoglobin and water. The peak excitation and emission wavelengths of ICG are 800nm and 840nm in blood, which are both within the optical window. Thus, the ICG fluorescence method can be used to provide assessment of blood vessels located relatively deep in the tissue (ref Mitsuo eBook). ]. Because ICG has amphiphilic characteristics, it binds to many plasmatic proteins and thus ICG is able to remain intravascular for a long time. Its fast binding to plasma proteins does not seem to alter protein structures, which is one sign of nontoxicity [52]. Since ICG is also not absorbed by the intestinal mucous membrane, it has very low toxicity. The safety of intravenously applied ICG in humans is very well documented with severe adverse reactions only in $0.05 \%$ of the cases [52]. The half-life is 2 to 4 minutes and it is removed from the circulation exclusively by the liver to bile juice. This short life time allows repeated applications. It must be stressed that ICG aqueous solutions are not very stable. Degradation is accelerated by exposure to light and high temperatures [53].

After light absorption, an excitated ICG molecule can follow three main pathways [53].

Firstly, the absorbed energy can be converted to a fluorescence emission. Maximum fluorescence is around $810 \mathrm{~nm}$ in water and $830 \mathrm{~nm}$ in blood. 
Secondly, a part of the energy is transferred to an ICG triplet state by intersystem crossing (ref Reindl). This triplet formation generates reactive oxygen species, in particular singlet oxygen. Singlet oxygen is a strong cytotoxic agent. The measured quantum yields of triplet formation is in the range of 10 to $20 \%$ and this is sufficiently high to generate efficient reactive oxygen species (ref Reindl . Engel et al [54] studied the stability of ICG when exposed to different light sources. Independently of the light source used, they suggest that ICG first produces singlet oxygen, although this was not detected, then further decomposition gives products that are responsible for the destruction of the cells. The mechanisms of actions are not clear because there is no direct proof of singlet oxygen.

Thirdly, the energy can be transformed into heat inside the ICG molecule. This is the major process after photon absorption because about $85 \%$ of absorbed light energy is converted to heat, a therapeutic procedure that can be used to achieve a specific tumor killing effect [53].

Because of its unstable optical properties and nonspecific localization, ICG can be encapsulated in nanoparticles. Nanoparticles are carriers for example for anti-cancer agent delivery but also protect the encapsultated drug against enzymes and hydrolysis. Yaseen et al showed that encapsulation of ICG within dextran-coated mesocapsules protected ICG from thermal degradation at different tested temperatures(ref Yaseen)). Due to their size, nanoparticles allow selective accumulation of the photosensitizer in the target cells. This could improve therapeutic applications of ICG because significant quantities at targeted sites can be achieved. 


\section{ICG applications}

ICG is mainly used as a very efficient fluorescent probe [52]. Established medical applications of ICG are retinal angiography, liver clearance test, and cardiac output monitoring.

Recent interest in ICG is based on new applications in surgery, especially in angiography related to intraoperative monitoring of blood circulation in vital organs.

ICG angiography used intraoperative is simple and devices are cheap. ICG is given as a bolus injection into the blood circulation and imaging is done a few minutes after injection. For example in micro neurosurgical vascular operations ICG angiography is very useful. In the exclusion of intracranial vascular malformations ICG angiography is able to verify that the malformation has been completely removed but normal blood flow remains uncompromised [52].

\section{ICG imaging in vascular surgery}

In vascular surgery ICG is used as an imaging tool in 3 relative new domains.

ICG perfusion imaging in vascular surgery has been studied in a perfusion rat model to diagnose peripheral arterial occlusive disease. Perfusion rates of lower extremities with severe peripheral arterial occlusive disease was significantly lower than those of normal controls [55].

ICG fluorescence imaging in the assessment of critical limb ischemia is a recent method of imaging the foot perfusion. In a pilot study from Venermo et al. [55], 41 patients with critical limb ischemia underwent ICG-fluorescence imaging after injecting ICG into the cephalic vein. ICG fluorescence imaging was quick to perform, easy to repeat due to rapid clearance of ICG 
and well tolerated. ICG fluorescence imaging in critical limb ischemia can be used to assess circulation at different sites, for example, at wound areas or the plantar side of the foot, which is not possible with transcutaneous oxygen pressure. Direct correlation of ICG fluorescence imaging with traditional measures, transcutaneous oxygen pressure or ankle brachial index, varied among the methods. This can be understood because all these methods measure circulation at different sites. However a strong correlation, especially in diabetic patients, was found between ICG fluorescence imaging and transcutaneous oxygen pressure. This can be explained because these two methods reflect local skin blood supply and media sclerosis does not have an impact on the results. ICG fluorescence imaging is therefore an additional tool in assessment of critical limb ischemia.

In lymphedema, ICG lymphangiography is popular as it clearly visualizes superficial lymph flow without radiation exposure. Even for evaluation of the effect of therapeutic compression in limb lymphedema, ICG lymphangiography is used [56].

Intravascular NIR fluorescence technology is used together with ICG to identify high-risk plaques. Lipid rich vulnerable plaques are the main cause of acute vessel occlusion in atherosclerosis. Methods are needed to detect coronary arterial plaques that are at risk for rupture. The group of Vinegoni et al $[57,58]$ demonstrated that ICG could rapidly target lipidrich atheroma in cholesterol-fed New Zealand white rabbits.

In summary, these studies demonstrate that ICG imaging is a very powerful tool. Use of ICG to evaluate perfusion and to identify vulnerable plaques is promising but additional ICG dosing and timing studies are further needed. Once these results are obtained, it is expected that clinical application of ICG imaging in vascular surgery will increase. 


\section{ICG for photodynamic applications}

ICG is mainly used as a fluorescent dye but has also been proposed as a photosensitizer. In combination with light it causes both in vitro and in vivo cytotoxic effects [53].

Publications with the use of ICG for photodynamic applications are numerous. In very common skin diseases as acne vulgaris, ICG and a diode laser has proven to be a very effective therapy [53]. Multidrug resistant bacteria as Pseudomonas aeruginosa are killed with photodynamic therapy and ICG as a near infrared photosensitizer. Recent publications describe the use of ICG for photodynamic therapy in multidrug resistant cancer and in treatment of nosocomial respiratory infections caused by resistant pathogens [59-61]. These are examples of what is called deep-tissue photodynamic therapy, photodynamic therapy with a photosensitizer active in the near infrared. These near-infrared wavelengths are able to penetrate deeper into human tissue compared with visible wavelength fluorescence compounds such as fluorescein (ref ebook).

The photodynamic effect of ICG is however still relative unclear. In a publication from Giraudeau et al (53] it is mentioned that there is cell destruction due to the production of reactive oxygen species but also an important thermal effect which causes selective photocoagulation. Moreover comparison between the conducted studies with ICG as a photosensitizer is difficult because of the great variety in the parameters like different ICG concentrations.

Although difficult to compare, it is clear that ICG for photodynamic applications is effective and well-tolerated. This is mainly due to basic properties like its amphiphilic characteristics and specific pharmokinetics (Table 3). Limitations of ICG for clinical applications like poor aqueous stability and lack of target specificity are solved by targeted photodynamic therapy. Several encapsulations have been implemented with ICG. Makino et al [62] have labeled lactosome with 
indocyanine green. The labeled lactosome was found to be stable in the blood circulation and accumulated specifically at a mouse model liver tumor site.

There are no data regarding the use of ICG as a photosensitizer in atherosclerosis. But some of the properties of ICG, as low toxicity and near infrared activity, point towards the great potential of ICG as a photosensitizer in atherosclerosis. In addition, the long and routine use of ICG in clinical applications will greatly facilitate its introduction in new applications.

\section{Conclusion}

In spite of the convincing evidence of in-vitro and in-vivo studies which confirmed the ability of photodynamic therapy to treat de novo or restenotic atherosclerotic lesions, this treatment has remained a research tool.

The failure of advancing the use of photodynamic therapy is mainly due to the absence of the ideal photosensitizer. Many of the studied photosensitizers have toxic effects of which a severe skin photosensitivity reaction is one of the most important.

ICG is a very powerful dye with long history and use in different clinical applications, mainly as a fluorescent probe. One of the recent studied fields is the imaging of lipid-rich plaques by near infrared fluorescence with the use of ICG. In photodynamic therapy, use of ICG as a safe photosensitizer is well documented.

Combining its properties as a very good imaging tool in atherosclerotic plaque and its capacities as photosensitizer in photodynamic therapy, ICG can be a good photosensitizer for the use of photodynamic therapy in atherosclerosis. There are no data available regarding the use of ICG as 
a photosensitizer in photodynamic therapy for atherosclerosis but this definitely deserves further research.

Funding

This research did not receive any specific grant from funding agencies in the public, commercial, or not-for-profit sectors.

Conflicts of interest

The authors have no financial or professional conflicts of interest. 


\section{Legends for Figures:}

- Fig. 1 Mechanims of action of photodynamic therapy. Photodynamic therapy requires three elements: light, a photosensitizer and oxygen. An activated photosensitizer releases energy, which is transferred to oxygen to generate reactive oxygen species such as singlet oxygen. These reactive oxygen species mediate cellular toxicity.

Reprinted from “ Photodynamic therapy for cancer “ by Dennis E.J.G.J. Dolmans, Dai Fukumura, Rakesh K. Jain. Nature 2003 May,vol 3.

- Fig. 2 Balloon angioplasty induces production of Reactive Oxygen Species. Reactive oxygen species are generated by different enzymatic systems, namely nicotinamide adenine dinucleotide phosphate. Reactive oxygen species stimulate smooth muscle cells and fibroblast proliferation and migration through the internal elastic lamina to form a neointimal layer leading to restenosis. Reprinted from "Oxidative stress and pathological changes after coronary artery interventions “by Rio P. Juni, Henricus J. Duckers. JACC 2013 April, vol 61.

- Fig. 3 Chemical structure of Indocyanine green. Retrieved from Wikipedia, The Free Encyclopedia. https://en.wikipedia.org/w/index.php?title=Indocyanine_green\&oldid=835788250

- Fig. 4 Excitation and emission spectra of ICG in blood plasma Retrieved from https://www.drugs.com/pro/indocyanine-green.html

- Fig. 5 Depending on the solvent and the dye concentration,the maximal absorption is observed between 600 and $900 \mathrm{~nm}$. In blood plasma the maximal absorption is at approximately $800 \mathrm{~nm}$. Retrieved from "personal data S. Mordon". 


\section{Table 1 Studies demonstrating the selective uptake of photosensitizer in atheromatous plaque}

\begin{tabular}{|c|c|c|c|c|c|}
\hline Photosensitizer & $\begin{array}{l}\text { Absorptio } \\
\mathbf{n} \\
\text { spectrum }\end{array}$ & Animal model & Dose & Major findings & $\begin{array}{l}\text { Referenc } \\
\text { es }\end{array}$ \\
\hline $\begin{array}{l}\text { Hemato- } \\
\text { porphyrin,photof } \\
\text { rin }\end{array}$ & $630 \mathrm{~nm}$ & $\begin{array}{l}\text { Rabbits } \\
\text { Monkey }\end{array}$ & $\begin{array}{l}2.5 \mathrm{mg} / \mathrm{kg} \\
\mathrm{IV}\end{array}$ & $\begin{array}{l}\text { Accumulation in } \\
\text { plaque }\end{array}$ & $22,23,24$ \\
\hline $\begin{array}{l}\text { 5-aminolevulinic } \\
\text { acid }\end{array}$ & $630 \mathrm{~nm}$ & $\begin{array}{l}\text { Rabbits } \\
\text { Pig }\end{array}$ & $\begin{array}{l}60- \\
120 \mathrm{mg} / \mathrm{kg} \\
\text { IV }\end{array}$ & $\begin{array}{l}\text { Uptake in plaque } \\
\text { Reduces } \\
\text { atherosclerosis } \\
\text { progression }\end{array}$ & 27,29 \\
\hline $\begin{array}{l}\text { Phthalocyanine } \\
\text { derivates }\end{array}$ & $670 \mathrm{~nm}$ & Rabbits & $\begin{array}{l}2.5^{-} \\
5 \mathrm{mg} / \mathrm{kg} \mathrm{IV}\end{array}$ & Uptake in plaque & 26 \\
\hline Verteporfin & $692 \mathrm{~nm}$ & $\begin{array}{l}\text { Rabbits } \\
\text { Miniswine }\end{array}$ & $2 \mathrm{mg} / \mathrm{kg} \mathrm{IV}$ & Uptake in plaque & 25 \\
\hline $\begin{array}{l}\text { Motexafin } \\
\text { lutetium }\end{array}$ & $710 \mathrm{~nm}$ & Rabbits & $\begin{array}{l}1.2 \mathrm{mg} / \mathrm{kg} \\
\text { IV or local } \\
\text { perfusion }\end{array}$ & $\begin{array}{l}\text { Uptake in plaque } \\
\text { Decrease in } \\
\text { atheroma burden }\end{array}$ & 17 \\
\hline
\end{tabular}

\section{Table 2 Studies demonstrating the effect of photodynamic therapy in management of restenosis}




\section{Table 3 Possible advantages and disadvantages of ICG as photosensitizer.}

\section{Advantages of ICG}

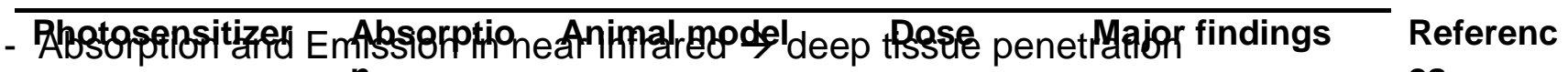
n es

- Only near infrared spyectrum approved by Food and drug administration

\begin{tabular}{|c|c|c|}
\hline 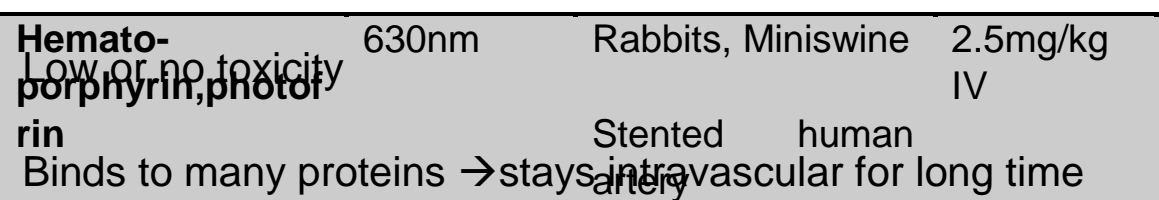 & $\begin{array}{l}\text { Photodynamic } \\
\text { therapy } \\
\text { prevented }\end{array}$ & $30,31,38-40$ \\
\hline Short half- life $\rightarrow$ repeated applications possible & $\begin{array}{l}\text { intimal } \\
\text { hyperplasia }\end{array}$ & \\
\hline $\begin{array}{l}\text { Cost-effective } \\
\text { Atheroma-targeting capability }\end{array}$ & $\begin{array}{l}\text { No } \\
\text { effects }\end{array}$ & \\
\hline $\begin{array}{l}\text { 5-aminolevulinic } 630 \mathrm{~nm} \text { Rabbits } \\
\text { acidn encapsulations } \rightarrow \text { more specific photodynamistherapy } \\
\text { pig } \\
\text { Long use in different clinical applications } \rightarrow \text { facilitates introduct }\end{array}$ & Photodynamic & 28,29 \\
\hline
\end{tabular}

Disadvantages of indocyanine green

- Lack of selectivity stent induced

$\begin{array}{lll}\text { Phthalocyanine } \quad 670 \mathrm{~nm} \quad \text { Rats } & 2.5- \\ \text { - Lopriyatestum yield of reactive oxygen species } & 5 \mathrm{mg} / \mathrm{kg} \text { IV }\end{array}$

- Rapid degeneration in moist environments intimal hyperplasia Photodynamic $\quad 33,37$

therapy prevented

- Instability in function of concentration, $\mathrm{pH}$, temperature and light exposure

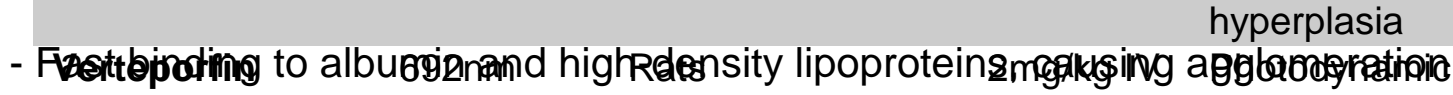
32 



\section{References}

[1] McGurnaghan S, Blackbourn LAK, Mocevic E, et al. Cardiovascular disease prevalence and risk factor prevalence in Type 2 diabetes: a contemporary analysis. Diabet Med. 2018 Sep 23 (Epub ahead of print)..

[1] Fowkes FG, Rudan D, Rudan I, et al. Comparison of global estimates of prevalence and risk factors for peripheral artery disease in 2000 and $2010:$ a systematic review and analysis. The Lancet. 2013;382:1329-40.

[2] Ricco JB, Parvin S, Veller M et al. Statement from the European Society of Vascular Surgery and the World Federation of Vascular Surgery Societies: Transatlantic Inter-Society Consensus Document (TASC) III and International Standards for Vascular Care (ISVaC). Eur J Vasc Endovasc Surg. 2014 Feb;47(2):118

[3] Van den Bergh. Drug-eluting balloons for treatment of SFA and popliteal disease - A review of current status. Eur J Radiol. 2017 Jun;91:106-115.

[4] Van den Berg JC. In-stent restenosis management: the best is yet to come. J. Cardiovasc Surg. 2017 Aug;58(4):508-517

[5] Heinen Y, Stegemann E, Sansone R, et al. Local association between endothelial dysfunction and intimal hyperplasia: relevance in peripheral artery disease. $\underline{\mathrm{JAm}}$ Heart Assoc. 2015 Feb 3;4(2).

[6] Roy T, Forbes T, Wright G, et al. Burning Bridges: Mechanisms and Implications of Endovascular Failure in the Treatment of Peripheral Artery Disease. $\underline{\text { J Endovasc }}$ Ther. 2015 Dec;22(6):874-80

[7] Krishnan P, Purushothaman KR, Purushothaman M et al. Enhanced neointimal fibroblast, myofibroblast content and altered extracellular matrix composition: Implications in the progression of human peripheral artery restenosis. Atherosclerosis. 2016 Aug;251:226-233

[8] Figge FHJ, Weiland GS. Cancer detection and therapy: Affinity of neoplastic, embryonic and traumatized tissues for porphyrins and metalloporphyrins. Proc Soc Exp Biol Med. 1948;68:640-641 
[9] Gomer CJ, Rucker N. Differential cell photosensitivity following porphyrin photodynamic therapy. Cancer Res 1988;48:4539-4542

[10] Henderson B, Dougherty Th. How does photodynamic therapy work? Photochemistry and photobiology vol 55,1:145-157

[11] Rockson SG, Lorenz DP, Cheong WF, et al. Photoangioplasty: An emerging clinical cardiovascular role for photodynamic therapy. Circulation. 2000 Aug 1;102(5):591-6

[12] Manish J, Mathieu Zellweger, Georges Wagnières, et al. Photodynamic therapy for the treatment of atherosclerotic plaque: lost in translation? Cardiovasc Ther. 2017 Apr;35(2)

[13] Oniszczuk A, Wojtunik-Kulesza KA, Oniszczuk T, et al. The potential of photodynamic therapy (PDT)-Experimental investigations and clinical use. Biomed Pharmacother. 2016 Oct;83:912-929

[13]. Dobson $\mathrm{J}^{1}$, de Queiroz $\mathrm{GF}^{2}$, Golding $\mathrm{JP}^{3}$. Photodynamic therapy and diagnosisi: principles and comparative aspects. Vet J. 2018 Mar;233:8-18.

[14] Muller JE. New light on an old problem photodynamic therapy for atherosclerosis. $J$ Am Coll Cardiol. 2008;52:1033-1034.

[15] Waksman R, McEwan PE, Moore TI, et al. Photopoint photodynamic therapy promotes stabilization of atherosclerotic plaques and inhibits plaque progression. $\mathrm{J} \mathrm{Am} \mathrm{Coll}$ Cardiol. 2008;52(12):1024-32

[16] Tang G, Hyman S, Schneider J, et al. Application of photodynamic therapy to the treatment of atherosclerotic plaques. Neurosurgery. 1993;32:438-443.

[17] Rockson SG, Lorenz DP, Cheong WF, et al. Photoangioplasty: An emerging clinical cardiovascular role for photodynamic therapy. Circulation. 2000 Aug 1;102(5):591-6 
[18] Nigri GR, Brini C, LaMuraglia GM, et al. Photodynamic therapy in cardiac and vascular surgery. G Chir. 2002 Aug-Sep;23(8-9):301-6.

[19] Krammer B. Vascular effects of photodynamic therapy. Anticancer Res. 2001 NovDec;21(6B):4271-7.

[20] Statius van Eps RG, ChandraSekar NR, Hasan T, et al. Importance of the treatment field for the application of vascular photodynamic therapy to inhibit intimal hyperplasia. Photochem Photobiol. 1998;67:337-342.

[21] Vincent G. Photodynamic therapy of atherosclerosis and restenosis: a potentially exciting new treatment method. SPIE. 1994;2130:2-10

[22] Spokojny AM, Serur JR, Skillman J, et al. Uptake of hematoporphyrin derivate by atheromatous plaques: studies in human in vitro and rabbit in vitro. $\mathrm{J} \mathrm{Am} \mathrm{Coll}$ Cardiol. 1986;8(6)

[23] Wooten RS, Smith KC, Ahlquist DA, et al. Prospective study of cutaneous phototoxicity after systemic hematoporphyrin derivative. Lasers Surg Med. 1988;8(3).

[24] Vincent G, Fox J, Charlton G, et al. Presence of blood significantly decreases transmission of $630 \mathbf{~ n m}$ laser light. Lasers Surg Med. 1991;11:399-403.

[25] Hsiang YN, Todd ME, Bower RD. Determining light dose for photodynamic therapy of atherosclerotic lesions in the Yucatan miniswine. J Endovasc Surg. 1995;2:365-371.

26 Allison B.A., Crespo M.T., et al. Delivery of benzoporphyrin derivate, a photosensitizer, into atherosclerotic plaque of watanabe heritable hyperlipidemic rabbits and balloon-injured new zealand rabbits. Photochemistry and Photobiology. 1997;65(5)

[26] Eldar M, Yerushalmi Y, Kessler E, et al. Preferential uptake of a water-soluble phthalocyanine by atherosclerotic plaques in rabbits. Atherosclerosis. 1990;84(2-3). 
[27] Pai M, Jamal W, Mosse A, et al. Inhibition of in-stent restenosis in rabbit iliac arteries with photodynamic therapy. Eur J Vasc Endovasc Surg. 2005;30:573-581

[28] Jenkins MP, Buonaccorsi G, MacRobert A, et al. Intra-arterial photodynamic therapy using 5-ALA in a swine model. Eur J Vasc Endovasc Surg. 1998;16:284-291

[29] Jenkins MP, Buonaccorsi GA, Mansfield R, et al. Reduction in the response to coronary and iliac artery injury with photodynamic therapy using 5-aminolaevulinic acid. Cardiovasc Res. 2000;45:478-485.

[30] Dartsch P, Ischinger T, Betz E. Responses of cultured smooth muscle cells from human nonatherosclerotic arteries and primary stenosing lesions after photoradiation: implication for photodynamic therapy of vascular stenosis. $\mathrm{J} \mathrm{Am} \mathrm{Coll} \mathrm{Cardiol.}$ 1990;15:1545-1550

[31] Dartsch P, Ischinger T, Betz E. Differential effect of Photofrin II on growth of human smooth muscle cells from non atherosclerotic arteries and atheromatous plaques in vitro. Atherosclerosis. 1990;10:616-624.

[32] Adili F, Statius van Eps R, Karp S, et al. Differential modulation of vascular endothelial and smooth muscle cell function by photodynamic therapy of extracellular matrix: novel insights into radical-mediated prevention of intimal hyperplasia. $J$ Vasc Surg. 1996;23:698-705.

[33] LaMuraglia GM, ChandraSekar NR, Flotte TJ, et al. Photodynamic therapy inhibition of experimental intimal hyperplasia: acute and chronic effects. $J$ Vasc Surg. 1994;19:321-329; discussion 9-31.

[34] Usui M, Asahara T, Naitoh Y, et al. Photodynamic therapy for the prevention of intimal hyperplasia in balloon-injured rabbit arteries. Jpn Circ J. 1999;63:387-393.

[35] Hsiang YN, Todd ME, Bower RD. Determining light dose for photodynamic therapy of atherosclerotic lesions in the Yucatan miniswine. J Endovasc Surg. 1995;2:365-371.

[36] Cheung J, Todd M, Turnbull R, et al. Longer term assessment of photodynamic therapy for intimal hyperplasia: a pilot study. J Photochem Photobiol, B. 2004;73:141-147 
[37] Ortu P, LaMuraglia GM, Roberts WG, et al. Photodynamic therapy of arteries. A novel approach for treatment of experimental intimal hyperplasia. Circulation. 1992;85:1189-1196.

[38] Eton D, Colburn MD, Shim V, et al. Inhibition of intimal hyperplasia by photodynamic therapy using Photofrin. J Surg Res, 53 (1992), pp. 558-562

[39] Eton D, Shim V, Maibenco TA, et al. Cytotoxic effect of photodynamic therapy with Photofrin II on intimal hyperplasia. Ann Vasc Surg. 1996;10:273-282.

[40] T Asahara, M Usui, T Amemiya, et al. The photodynamic therapy for the prevention of restenosis after angioplasty. Society of Photo-Optical Instrumentation Engineers, 1878 (1993)

[41] H Hanke, T Strohschneider, M Oberhoff, E Betz, et al. Time course of smooth muscle cell proliferation in the intima and media of arteries following experimental angioplasty. Circ Res, 67 (1990), pp. 651-659

[42] Hsiang YN1, Crespo MT, Todd ME. Dosage and timing of Photofrin for photodynamic therapy of intimal hyperplasia. Cardiovasc Surg. 1995 Oct;3(5):489-94.

[43] Jenkins MP, Buonaccorsi GA, Raphael M, et al. Clinical study of adjuvant photodynamic therapy to reduce restenosis following femoral angioplasty. $\mathrm{Br} J$ Surg. 1999;86:1258-1263.

[44] Rockson SG, Kramer P, Razavi M, et al. Photoangioplasty for human peripheral atherosclerosis: results of a phase I trial of photodynamic therapy with motexafin lutetium (Antrin). Circulation. 2000;102:2322-2324.

[45] Kereiiakes D, Szyniszewski A, et al. Phase I drug and light dose-escalation trial of motaxafin lutetium and far red light activation in subjects with coronary artery disease undergoing percutaneous coronary intervention and stent deployment. Circulation. 2003;108:1310-1315.

Usui M, Miyagi M, Fukasawa S, et al. A first trial in the clinical application of photodynamic therapy for the prevention of restenosis after coronary-stent placement. Lasers Surg Med. 2004;34:235-241 
[46] Kossodo S, LaMuraglia GM. Clinical potential of photodynamic therapy in cardiovascular disorders. Am J Cardiovasc Drugs. 2001;1(1):15-21

[47] Magaraggia M, Marigo L, Pagnan A, et al. Porphyrin-photosensitized processes: their applications in the prevention of arterial restenosis. Cardiovasc Hematol Agents Med Chem. 2007 Oct;5(4):278-88.

[48] Muragaki Y, Akimoto J, Maruyama T, et al. Phase II clinical study on intraoperative photodynamic therapy with talaporfin sodium and semiconductor laser in patients with malignant brain tumors. J Neurosurg. 2013;119:845-852.

[49] Nyamekye I, Anglin S, McEwan J et al. Photodynamic therapy of normal and ballooninjured carotid arteries using 5-amino-levulinic acid. Circulation 1995; 91: 417-425

[50] Fox IJ.; Wood EH. Indocyanine Green: physical and physiological properties. Proc. Staff Meet mayo Clin 1957,32(18),478-484

[51] Desmettre T, Devoiselle JM, Mordon S. Fluorescence Properties and Metabolic Features of Indocyanine Green as related to Angiography. Survey of Ophthalmology ,vol 45, july-aug 2000

[52] Alander JT, Kaartinen I, Laakso A, Pätilä T et al. A review of indocyanine green fluorescent imaging in surgery. Int J Biomed Imaging. 2012;2012:940585.

[53] Giraudeau C, Moussaron A, Mordon S et al. Indocyanine green: photosensitizer or chromophore? Still a debate. Curr Med Chem. 2014;21(16):1871-97.

[54] E. Engel, R.Schraml et al. Light induced decomposition of Indocyanine green. Investigative Ophthalmology and visual science,vol 49,no 5,1777-1783,2008

[55] Venermo M, Settembre N, Albäck A, et al. Pilot Assessment of the Repeatability of Indocyanine Green Fluorescence Imaging and Correlation with Traditional Foot Perfusion Assessments. Eur J Vasc Endovasc Surg. 2016 Oct;52(4):527-533 
[56] Zaleska Mt, Olszewski WL. Indocyanine green near- infrared lymphangiography for evaluation of effectiveness of edema fluid flow under therapeutic compression.

J Biophotonics. 2017 Jul 20

[57] Vinegoni C, Botnaru I, Aikawa E, et al. Indocyanine green enables near-infrared fluorescence imaging of lipid-rich, inflamed atherosclerotic plaques. Sci Transl Med. 2011 May 25;3(84)

[58] Mehta NN, Rader DJ. Fluorescent green plaques: light at the end of the catheter? Cell Metab. 2011 Jul 6;14(1):7-8

[59] Geralde MC, Leite IS, Inada NM, et al. Pneumonia treatment by photodynamic therapy with extracorporeal illumination - an experimental model. Physiol Rep. 2017 Mar;5(5).

[60] Luo T, Zhang Q, Lu QB. Combination of Near Infrared Light-Activated Photodynamic Therapy Mediated by Indocyanine Green with Etoposide to Treat Non-Small-Cell Lung Cancer. Cancers (Basel). 2017 Jun 5;9(6)

[61] Dennis E.J.G.J. Dolmans, Dai Fukumura, Rakesh K. Jain. Photodynamic therapy for cancer. Nature 2003 May,vol 3

[62] Makino A, Kizaka-Kondoh S, Yamahara R, et al. Near-infrared fluorescence tumor imaging using nanocarrier composed of poly(l-lactic acid)-block-poly(sarcosine) amphiphilic polydepsipeptide. Biomaterials, vol. 30, no. 28, pp. 5156-5160, 2009.

Gomes A, Neves M, Cavaleiro J. Cancer, photodynamic therapy and phorphyrin-type derivates. An Acad Bras Cienc 201890

Reindl S.,Penzkofer A.,Gong S,et al. Quantum yield of triplet formation for indocyanine green. J. Photochem. Photobiol.1997,105(1)

Yaseen M.,Yu J.,Wong M. et al. Stability assessment of indocyanine green within dextrancoated mesocapsules by absorbance spectroscopy. J. Biomed. Opt. 2007,12(6). 
